\title{
TRẮC NGHIỆM EWINGS VÀ BIẾN CHÚN NG THẦN KINH TỬ CHỦ TIM MẠCH Ở BỆNH NHÂN ĐÁI THÁO ĐƯỜNG
}

\author{
Văn Thị Thu Hiền ${ }^{1}$, Vũ Bích Nga ${ }^{2}$, Lê Đình Tùng ${ }^{1}$
}

DOI: $10.47122 / v j d e .2020 .45 .15$

1. Truờng Đại học Y Hà Nội; 2. Bệnh viện Đại học Y Hà Nội

\section{TÓM TẮT}

Bệnh thần kinh tự chủ tim mạch là một trong những biến chứng nghiêm trọng nhưng ít được chẩn đoán ở bệnh nhân đái tháo đường. Tỷ lệ bệnh thần kinh tự chủ tim mạch thay đồi từ $2 \%$ đến $91 \%$ ở đái tháo đường típ 1 (ĐTĐ típ 1) và $25 \%$ đến $75 \%$ ở đái tháo đường típ 2 (ĐTĐ típ 2). Kết quả có sự khác nhau đáng kể giữa các nghiên cứu là do thiếu sự thống nhất giữa các tiêu chuẩn chẩn đoán. Biểu hiện bệnh bao gồm hạ huyết áp tư thế, nhịp tim nhanh khi nghỉ, và có thể có nhồi máu cơ tim thầm lặng. Có nhiều phương pháp để chẩn đoán bênh, bao gồm sử dụng các nghiệm pháp để đánh giá chức năng thần kinh giao cảm và phó giao cảm. Đây là một biến chứng muộn, và một khi đã xảy ra thì việc đảo ngược tình trạng này là không thể. Điều trị bệnh thần kinh tự chủ tim mạch còn rất hạn chế, chủ yếu điều trị kiểm soát triệu chứng hạ huyết áp tư thế. Bài viết này trình bày về phương pháp thăm dò phát hiện sớm biến chứng thần kinh tự chủ tim mạch bằng các xét nghiệm không xâm lấn đơn giản để đo chức năng tự chủ của tim dựa trên đáp ứng của nhịp tim và huyết áp với vận động sinh lý. Thăm dò này được Ewing và cộng sự mô tả đầu tiên vào năm 1980 và đã được áp dụng hiệu quả trong việc phát hiện sớm những thay đổi trong chức năng thần kinh tự chủ ở bệnh nhân đái tháo đường.

Tù khóa: Bệnh thần kinh tụ chủ tim mạch, đái tháo đường

\section{ABSTRACT \\ Ewing tests and Cardiovascular autonomic neuropathy in diabetic patients \\ Van Thi Thu Hien', Vu Bich $\mathrm{Nga}^{2}$, Le Dinh Tung ${ }^{1}$ \\ 1. Ha Noi Medical University; 2. Ha Noi Medical University Hospital}

Cardiovascular autonomic neuropathy
(CAN) is a severely complication yet underdiagnosed condition in patients with diabetes. The prevalence of CAN is variable based on published studies and ranges from $2 \%$ to $91 \%$ in type I diabetes mellitus (T1DM) and $25 \%$ to $75 \%$ in type 2 diabetes (T2DM). This significant variability can likely be attributed to the lack of a uniform diagnostic criteria. Cardiovascular effects of diabetic autonomic neuropathy include postural hypotension, resting tachycardia, and, possibly, painless myocardial infarction. The diagnosis is made using multiple autonomic function tests to assess both sympathetic and parasympathetic function. However, Treatment is limited to symptomatic control of orthostatic hypotension, which is a late complication, and current strategies to reverse CAN are impossible. This review explores the early detection of cardiovascular autonomic neurological complications can be assessed using simple noninvasive tests based on the response of heart rate and blood pressure with physiological movement. Cardiac autonomic reflex tests (CARTs) were first described by Ewing et al in 1980 and and has been used effectively in early detection of changes in autonomic nerve function in diabetic patients.

Key words: Cardiac autonomic neuropathy, diabetes.

Chịu trách nhiệm chính: Văn Thị Thu Hiền

Ngày nhận bài: 5/1/2021

Ngày phản biện khoa học: 11/1/2021

Ngày duyệt bài: 4/3/2021

Email: hienk49ct@gmail.com

\section{DİCH TẼ}

Tỷ lệ bệnh thần kinh tự chủ tim mạch thay đổi từ $2 \%$ đến $91 \%$ ở ĐTĐ type I và $25 \%$ đến $75 \%$ ở ĐTĐ típ 2 [2], [3]. Có sự khác nhau đáng kể giữa các kết quả nghiên cứu là do thiếu sự thống nhất giữa các tiêu chuẩn chẩn đoán 
$[2,4]$. Dựa trên thử nghiệm Diabetes Control and Complications Trial (DCCT) / nghiên cứu Epidemiology of Diabetes Interventions and Complications (EDIC) tỷ lệ mắc bệnh ở bệnh nhân ĐTĐ típ 1 sau 15 năm đã gần $60 \%$ [2], [5], [6], [7]. Mặc dù bệnh có liên quan đến thời gian mắc ĐTĐ nhưng bệnh xảy ra ở cả những bệnh nhân ĐTĐ mới phát hiện và tiền đái tháo đường với một tỷ lệ nhỏ trong một vài nghiên cứu [2], [5]. Theo khuyến cáo của hội đồng đồng thuận Toronto về bệnh lý thần kinh ở ĐTÐ (Toronto Consensus Panel on Diabetic Neuropathy) nên đánh giá biến chứng thần kinh tự chủ tim mạch ngay tại thời điểm chẩn đoán ĐTĐ típ 2 và ĐTĐ típ 1 phát hiện trên 5 năm, đặc biệt ở những bệnh nhân có nhiều yếu tố nguy cơ, như kiểm soát đường huyết kém, hút thuốc, tăng huyết áp, hoặc rối loạn lipid máu. Hội đồng cũng khuyến nghị rằng sàng lọc là một phần trong đánh giá nguy cơ phẫu thuật ở bệnh nhân mắc bệnh mạch vành.

\section{CÁC PHƯƠNG PHÁP CHẨN ĐOÁN}

Vào đầu những năm 1970 Ewing và cộng sự lần đầu tiên đưa ra các xét nghiệm không xâm lấn đơn giản để đo chức năng tự chủ của tim dựa trên đáp ứng của nhịp tim và huyết áp với vận động sinh lý [1]. Các nghiệm pháp chẩn đoán của Ewing bao gồm:

1. Đáp ứng nhịp tim với nhịp thở sâu bằng cách đánh giá biến đổi nhịp tim qua biến đổi khoảng R-R

2. Thay đổi nhịp tim khi đứng, được biểu thị theo tỷ lệ 30:15 là tỷ lệ của khoảng thời gian R-R dài nhất (giữa nhịp 20 và 40 ) đến khoảng R-R ngắn nhất (giữa nhịp 5-25) gây ra bởi sự thay đổi từ vị trí nằm sang đứng

3. Nghiệm pháp Valsalva để đánh giá phản ứng nhịp tim trong và sau khi tăng áp lực trong lồng ngực và trong ổ bụng (được thực hiện bằng cách cho bệnh nhân thở ra trong khoảng thời gian 15 giây chống lại một lực cố định).

4. Phản ứng huyết áp khi thay đổi tư thế từ nằm sang đứng bằng cách đánh giá thay đổi huyết áp trung bình sau thay đổi tư thế.

5. Phản ứng huyết áp với duy trì lực kế cầm tay, biểu hiện bằng tăng huyết áp tâm trương gây ra bởi sự co cơ kéo dài với việc sử dụng của một lực kế tay cầm.

Hai nghiệm pháp đầu đánh giá khiếm khuyết trong hoạt động phó giao cảm (PGC) (tức là, khả năng của dây thần kinh phế vị làm chậm nhịp tim với biểu hiện tăng khoảng $\mathrm{R}-\mathrm{R}$ ), hai nghiệm pháp cuối mô tả những thay đổi trong chức năng giao cảm (GC) (nghĩa là khả năng cung cấp phản ứng huyết áp và nhịp tim phù hợp cho hoạt động liên quan). Những thay đổi tự động xảy ra trong khi làm nghiệm pháp Valsalva rất phức tạp và liên quan đến cả hệ thống $\mathrm{GC}$ và $\mathrm{PGC}$. Trắc nghiệm Ewing là tiêu chuẩn vàng để chẩn đoán bệnh thần kinh tự chủ tim mạch. Các giá trị tham chiếu phụ thuộc vào tuổi. Chỉ một nghiệm pháp bất thường là đủ để chẩn đoán bệnh ở giai đoạn sớm. Hai hoặc nhiều nghiệm pháp bất thường là đủ để chẩn đoán xác định. Sự có mặt của hạ huyết áp thế cho thấy bệnh ở giai đoạn nặng [9]. Hiệp hội ĐTĐ Mỹ khuyến cáo sử dụng các xét nghiệm Ewing trong chẩn đoán bệnh thần kinh tự chủ tim mạch [8]. Một phương pháp khác chẩn đoán bệnh như sự thay đổi nhịp tim đánh giá trong suốt 24 giờ theo dõi Holter điện tim đồ cổ điển. Giảm biến đổi nhịp tim có liên quan đến bênh, nhưng phương pháp này không có giá trị làm tiêu chuẩn chẩn đoán [9]. Ngoài ra, trong 24 giờ ghi, nhiều yếu tố có thể ảnh hưởng đến các thông số nhịp tim, chẳng hạn như bệnh đồng mắc, sử dụng thuốc và các yếu tố liên quan đển lối sống (tập thể dục, căng thẳng, hút thuốc, v.v.).

Phản xạ baroreceptor (BRR) là một phương pháp khác có thể được sử dụng để phát hiện bệnh. Trong phản xạ baroreceptor sinh lý, tăng HA làm giảm hoạt động giao cảm, dẫn đến nhịp tim chậm, hạ huyết áp và giãn mạch ngoại biên [9]. Giảm HA gây ra phản ứng ngược lại. Thử nghiệm này có thể được sử dụng để phát hiện bệnh và gần giống với các trắc nghiệm Ewing cổ điển [10]. 


\section{TÓM TẮT TRẮC NGHIỆM CỦA EWINGS}

\begin{tabular}{|c|c|c|c|c|}
\hline Ewing tests & Đánh giá & $\begin{array}{l}\text { Phần hệ thần kinh tự } \\
\text { chủ được đánh giá }\end{array}$ & $\begin{array}{l}\text { Giải thích và định } \\
\text { nghĩa }\end{array}$ & $\begin{array}{l}\text { Khoảng } \\
\text { tham chiếu } \\
\text { theo tuổi }\end{array}$ \\
\hline $\begin{array}{l}\text { 1. Đáp ứng } \\
\text { nhịp tim } \\
\text { với hít thở } \\
\text { sâu }\end{array}$ & $\begin{array}{l}\text { Biến đổi nhịp tim } \\
\text { theo nhịp hít thở } \\
\text { sâu (khoảng R-R) }\end{array}$ & $\begin{array}{l}\text { Đánh giá hoạt động } \\
\text { GC: Khả năng thần } \\
\text { kinh phế vị làm } \\
\text { chậm nhịp tim }\end{array}$ & $\begin{array}{l}\text { Tỷ lệ } \\
\text { E / I = R-R } \\
\text { Dài nhất khi thở ra / } \\
\text { Ngắn nhất khi hít vào }\end{array}$ & $\begin{array}{l}1,22-1,1 \\
(15-65 \\
\text { tuổi) }\end{array}$ \\
\hline $\begin{array}{l}\text { 2. Đáp ứng } \\
\text { nhịp tim } \\
\text { với thay } \\
\text { đổi tư thế }\end{array}$ & $\begin{array}{l}\text { Biến đổi nhịp tim } \\
\text { sau khi đứng }\end{array}$ & $\begin{array}{l}\text { Đánh giá hoạt động } \\
\text { GC: Khả năng thần } \\
\text { kinh phế vị làm } \\
\text { chậm nhịp tim }\end{array}$ & $\begin{array}{l}\text { Tỷ lệ } 30: 15 \text { : Khoảng } \\
\text { R-R xung quanh nhịp } \\
\text { tim thứ } 30 / \text { khoảng } \\
\text { R-R xung quanh nhịp } \\
\text { tim thứ } 15\end{array}$ & $\begin{array}{l}1,17-1,06 \\
(15-65 \\
\text { tuổi })\end{array}$ \\
\hline $\begin{array}{l}\text { 3. Nghiệm } \\
\text { pháp } \\
\text { Valsaval }\end{array}$ & $\begin{array}{l}\text { Biến đổi nhịp tim } \\
\text { khi thay đổi áp lực } \\
\text { ổ bụng/ nội sọ }\end{array}$ & $\begin{array}{l}\text { Đánh giá cả hoạt } \\
\text { động GC và PGC, } \\
\text { chủ yếu là } G C\end{array}$ & $\begin{array}{l}\text { Tỷ lệ Valsalva: } \\
\text { Khoảng R-R dài nhất } \\
\text { / khoảng thời gian R- } \\
\text { R ngắn nhất }\end{array}$ & $\begin{array}{l}1,23-1,16 \\
(15-65 \\
\text { tuổi) }\end{array}$ \\
\hline $\begin{array}{l}\text { 4. Đáp ứng } \\
\text { huyết áp } \\
\text { với tư thế } \\
\text { đứng }\end{array}$ & $\begin{array}{l}\text { Đánh giá phản xạ } \\
\text { nhận cảm huyết áp } \\
\text { (HA) }\end{array}$ & $\begin{array}{l}\text { Kiểm tra các khiếm } \\
\text { khuyết trong hoạt } \\
\text { động GC bằng cách } \\
\text { đánh giá phản xạ đáp } \\
\text { ứng nhịp tim và HA }\end{array}$ & $\begin{array}{l}\text { Đánh gia thay đổi HA } \\
\text { tâm thu và tâm trương } \\
\text { khi nằm và đứng }\end{array}$ & $\begin{array}{l}\text { Giảm từ } \\
20 \mathrm{mmHg} \\
\mathrm{HA} \text { tâm } \\
\text { thu, từ } \\
10 \mathrm{mmHg} \\
\mathrm{HA} \mathrm{tâm} \\
\text { trương trở } \\
\text { lên }\end{array}$ \\
\hline $\begin{array}{l}\text { 5.Đáp ứng } \\
\text { huyết áp } \\
\text { với co cơ } \\
\text { liên tục }\end{array}$ & $\begin{array}{l}\text { Tăng HA tâm } \\
\text { trương gây ra bởi } \\
\text { sự co cơ kéo dài }\end{array}$ & $\begin{array}{l}\text { Đánh giá hoạt động } \\
\text { GC bằng cách đáp } \\
\text { ứng nhịp tim và } \\
\text { huyết áp phù hợp với } \\
\text { hạt động }\end{array}$ & $\begin{array}{l}\text { Đánh giá huyết áp } \\
\text { tâm trương khi hoạt } \\
\text { động trừ đi khi nghỉ } \\
\text { ngơi }\end{array}$ & $\begin{array}{l}\text { Lớn hơn } \\
15 \mathrm{mmHg}\end{array}$ \\
\hline
\end{tabular}

\section{KẾT LUẬN}

Bệnh thần kinh tự chủ tim mạch rất phổ biến nhưng thường ít được chẩn đoán ở bệnh nhân ĐTĐ. Thay đổi lối sống, kiểm soát đường máu và các yếu tố nguy cơ bệnh mạch vành làm hạn chế sự xuất hiện và tiến triển của bệnh. Tuy nhiên chẩn đoán sớm bệnh rất cần thiết, liên quan đến tỷ lệ tử vong, bệnh mạch vành, bệnh thận mạn và các biến chứng mạch máu ngoại vi của ĐTĐ. Vì vậy, cần được theo dõi, chẩn đoán và điều trị dự phòng sớm và phù hợp ở bệnh nhân ĐTĐ để ngăn ngừa và làm chậm tiến triển của bệnh. Trắc nghiệm Ewing là một trong những phương pháp đơn giản, rẻ tiền có giá trị để thăm dò và phát hiện sớm bệnh.

\section{TÀI LIỆ THAM KHẢO}

1. D. J. Ewing, I. W. Campbell, and B. F. Clarke. Assessment of cardiovascular effects in diabetic autonomic neuropathy and prognostic implications. Annals of Internal Medicine, vol. 92, no. 2, Part 2, pp. 308-311, 1980

2. Dimitropoulos G, Tahrani AA, Stevens MJ. Cardiac autonomic neuropathy in patients with diabetes mellitus. World J Diabetes. 2014 Feb 15;5(1):17-39.

3. Vinik AI, Ziegler D. Diabetic cardiovascular autonomic neuropathy. Circulation. 2007 Jan 23;115(3):387-97. 
4. Ziegler D, Gries FA, Spüler M, Lessmann F. The epidemiology of diabetic neuropathy. Diabetic Cardiovascular Autonomic Neuropathy Multicenter Study Group. J Diabetes Complications. 1992 Jan-Mar;6(1):49-57.

5. Vinik AI, Erbas T, Casellini CM. Diabetic cardiac autonomic neuropathy, inflammation and cardiovascular disease. J Diabetes Investig. 2013 Jan;4(1):4-18.

6. Balcioglu AS, Müderrisoglu H. Diabetes and cardiac autonomic neuropathy: Clinical manifestations, cardiovascular consequences, diagnosis and treatment. Diabetes Care. 2010 Feb;33(2):434-41.

7. Diabetes Control and Complications Trial Research Group. The effect of intensive diabetes therapy on measures of autonomic nervous system function in the Diabetes Control and Complications Trial
(DCCT). Diabetologia. 1998 Apr;41(4):416-23.

8. A. J. M. Boulton, A. I. Vinik, J. C. Arezzo et al.Diabetic neuropathies: a statement by the American Diabetes Association.Diabetes Care, vol. 28, no. 4, pp. 956-962, 2005.

9. L. Bernardi, V. Spallone, M. Stevens et al..Methods of investigation for cardiac autonomic dysfunction in human research studies.Diabetes/Metabolism Research and Reviews, vol. 27, no. 7, pp. 654-664, 2011.

10. E. Borowik, W. Grabowicz, T. Grycewicz, and A. Lubiński.Clinical usefulness of baroreflex sensitivity test in the detection of cardiovascular autonomic neuropathy in patients with type 2 diabetes mellitus.Polski Merkuriusz Lekarski, vol. 39, no. 233, pp. 277-280, 2015. 